\title{
HUBUNGAN TINGKAT PENGETAHUAN IBU HAMIL DENGAN PARTISIPASI KELAS IBU HAMIL DI WILAYAH KERJA PUSKESMAS 2 CILONGOK BANYUMAS
}

\author{
Diah Atmarina Yulliani \\ Email: yuliani_da@yahoo.com \\ Kebidanan DIII FIKES Universitas Muhammadiyah Purwokerto \\ Jl. Letjen Soepardjo Roestam Km. 7 Purwokerto 53181 \\ Telp/Fax (0281) 6844252)
}

\begin{abstract}
Abstrak
Kehamilan dan persalinan adalah suatu hal yang alami akan tetapi bukan berarti tanpa resiko, masalah kehamilan dan persalinan adalah penyumbang terbesar Angka Kematian Ibu dan Angka Kematian Bayi. Salah satu terobosan untuk meningkatkan pengetahuan ibu hamil dengan melalui kelas ibu hamil, namun demikian banyak ibu yang belum berpartisipasi dalam mengikuti kelas ibu hamil. Penelitian ini bertujuan untuk mengetahui pengetahuan ibu hamil, mengetahui partisipasi kelas ibu hamil, menganalisis hubungan antara pengetahuan ibu hamil dengan partisipasi kelas ibu hamil. Desain korelasional dengan pendekatan cross sectional. Jumlah sampel 64 diambil dengan cara sampling jenuh. Pengumpulan data dengan menggunakan kuesioner. Uji statistik menggunakan uji spearman rank. Hasil penelitian menunjukkan ibu hamil memiliki pengetahuan baik sebesar $43,8 \%$ dan berpartisipasi $68,8 \%$ dalam kelas ibu hamil. Ada hubungan yang signifikan antara variabel pengetahuan dengan partisipasi dalam kelas ibu hamil $\left(\rho=0,000, r_{s}\right.$ 0,554). Kelas ibu hamil merupakan sarana belajar bersama yang perlu diikuti oleh ibu hamil agar memperoleh pengetahuan yang cukup sehingga dapat mencegah komplikasi dan meningkatkan cakupan K4. Disarankan meningkatkan pembentukan kelas ibu hamil agar kehamilan dapat terpantau dan ibu dapat segera mengambil keputusan klinis apabila terjadi resiko.
\end{abstract}

Kata kunci: Pengetahuan, partisipasi, kelas ibu hamil.

\section{Pendahuluan}

Pembangunan berkelanjutan SDG's (sustainable Development Goals) pada tujuan ketiga yaitu menjamin kehidupan yang sehta dan mendorong kesejahteraan bagi smeua orang di segala usia, yaitu pada tahun 20130. Menurut tujuan SDG's terkait kesehatan ibu danbayi, target AKI yaitu di bawah 70 per 100.000 kelahiran hidup. Target untuk angka kematian neonatal yaitu 12 per 1000 kelahiran hidup. ${ }^{3}$

Kelas Ibu Hamil adalah kelompok belajar ibu-ibu hamil dengan umur kehamilan antara 4 minggu s/d 36 minggu (menjelang persalinan) dengan jumlah peserta maksimal $10 \mathrm{ibu}$ hamil. Tujuan diadakannya kelas ibu hamil adalah untuk menambah pengetahuan ibu tentang kesehatan ibu dan anak, sehingga dapat mengurangi terjadinya angka kematian ibu dan angka kematian bayi. ${ }^{1}$

Pertemuan kelas ibu hamil dilakukan 3 kali pertemuan selama hamil atau sesuai dengan hasil kesepakatan fasilitator. Tingkat pengetahuan seseorang biasanya akan mempengaruhi pola pikirnya, baik terhadap kehidupan sosial maupun kesehatan.
Seseorang dengan pengetahuan yang baik akan memprioritaskan kesehatan dalam hidupnya dengan partisipasinya dalam mengikuti kelas ibu hamil daripada orang yang pengetahuan yang kurang baik. ${ }^{1}$

Keterbatasan pengetahuan akan menyulitkan seseorang memahami pentingnya pemeliharaan kesehatan dan perubahan perilaku seseorang ke arah yang menguntungkan kesehatan. Berbagai hal yang memepengaruhi tinggi rendahnya pengetahuan dan partisipasi ibu hamil dalam kelas ibu hamil, diantaranya tingkat pengetahuan ibu hamil dan partisipasi ibu hamil. $^{2}$

Berdasarkan studi pendahuluan terhadap 10 ibu hamil di Puskesmas 2 Cilongok Kabupaten Banyumas, peneliti menemukan sebanyak 8 ibu hamil tidak mengetahui tentang kelas ibu hamil dengan partisipasi kelas ibu hamil, dan 2 ibu hamil sudah mengetahui tentang kelas ibu hamil dengan partisipasi kelas ibu hamil. Berdasarkan uraian di atas, peneliti tertarik untuk melakukan penelitian tentang hubungan tingkat pengetahuan ibu hamil 
dengan partisipasi kelas ibu hamil di wilayah kerja Puskesmas 2 Cilongok Kabupaten Banyumas.

\section{Metode Penelitian}

Penelitian ini adalah penelitian kuantitatif dengan menggunakan desain korelasional dengan pendekatan Cross Sectional. Dalam penelitian ini digunakan untuk mengetahui hubungan tingkat pengetahuan ibu hamil dengan partisipasi kelas ibu hamil di wilayah kerja Puskesmas 2 Cilongok Kabupaten Banyumas. Populasi dalam penelitian ini adalah seluruh ibu hamil usia kehamilan 4 sampai 36 mingggu di wilayah kerja Puskesmas 2 Cilongok Kabupaten Banyumas.

Penelitian ini menggunakan sampel yang berada di wilayah kerja Puskesmas 2 Cilongok Kabupaten Banyumas sebanyak 64 orang dengan kriteria inklusi dan eksklusi. Teknik pengambilan sampel yang digunakan adalah sampling jenuh. Teknik pengumpulan data menggunakan data primer dan sekunder. Data primer diperoleh dengan membagikan kuesioner kepada responden. Data sekunder diperoleh dari Puskesmas 2 Cilongok Kabupaten Banyumas.

\section{Hasil dan Pembahasan}

Karakteristik responden pada penelitian ini berdasarkan umur, pendidikan, usia kehamilan.

\begin{tabular}{|c|c|c|c|}
\hline No & Umur & $\begin{array}{l}\text { Frekuensi } \\
\text { (f) }\end{array}$ & $\begin{array}{c}\text { Presentase } \\
(\%)\end{array}$ \\
\hline 1 & $\begin{array}{l}\text { Kurang } \\
\text { dari } 26 \\
\text { Tahun }\end{array}$ & 32 & 50,0 \\
\hline 2 & $\begin{array}{l}26-30 \\
\text { Tahun }\end{array}$ & 22 & 34,4 \\
\hline 3 & $\begin{array}{l}\text { Lebih dari } \\
30 \text { Tahun }\end{array}$ & 10 & 15,6 \\
\hline & Total & 64 & 100 \\
\hline
\end{tabular}

Tabel 1. Distribusi frekuensi umur ibu hamil di wilayah kerja Puskesmas 2 Cilongok Kabupaten Banyumas.

Penelitian ini menunjukkan bahwa umur responden kurang dari 26 tahun sebanyak 32 ibu hamil $(50,0 \%), 26-30$ tahun sebanyak 22 ibu hamil $(34,4 \%)$ dan yang berumur lebih dari 30 tahun sebanyak $10 \mathrm{ibu}$ hamil $(15,6 \%)$.

Tabel 2. Distribusi frekuensi pendidikan ibu hamil di wilayah Puskesmas 2 Cilongok Kabupaten Banyumas

\begin{tabular}{cccc}
\hline No & Pendidikan & $\begin{array}{c}\text { Frekuensi } \\
\text { (f) }\end{array}$ & $\begin{array}{c}\text { Presentase } \\
(\%)\end{array}$ \\
\hline 1 & SD & 6 & 9,4 \\
& & & \\
2 & SMP & 28 & 43,8 \\
3 & SMA & 25 & 39,1 \\
4 & D3 & 5 & 7,8 \\
\hline & Total & 64 & 100 \\
\hline
\end{tabular}

Berdasarkan tabel 2 di atas menunjukkan bahwa responden yang berpendidikan SD sebanyak 6 ibu hamil $(9,4 \%)$, SMP sebanyak 28 ibu hamil (43,8\%), SMA sebanyak 25 ibu hamil $(39,1 \%)$, dan yang berpendidikan D3 hanya 5 ibu hamil $(7,8 \%)$.

Tabel 3. Distribusi frekuensi usia kehamilan ibu hamil di wilayah Puskesmas 2 Cilongok Kabupaten Banyumas

Analisis univariat

\begin{tabular}{cccc}
\hline No & $\begin{array}{c}\text { Usia } \\
\text { Kehamilan }\end{array}$ & $\begin{array}{c}\text { Frekuensi } \\
\text { (f) }\end{array}$ & $\begin{array}{c}\text { Presentase } \\
(\%)\end{array}$ \\
\hline 1 & Trimester 1 & 1 & 1,6 \\
2 & Trimester 2 & 39 & 60,9 \\
3 & Trimester 3 & 24 & 37,5 \\
\hline & Total & 64 & 100 \\
\hline
\end{tabular}

Tabel 4. Distribusi frekuensi pengetahuan ibu hamil di wilayah Puskesmas 2 Cilongok Kabupaten Banyumas.

\begin{tabular}{cccc}
\hline No & Pengetahuan & $\begin{array}{c}\text { Frekuensi } \\
(\mathrm{f})\end{array}$ & $\begin{array}{c}\text { Presentase } \\
(\%)\end{array}$ \\
\hline 1 & Baik & 28 & 43,8 \\
2 & Cukup & 17 & 26,6 \\
3 & Kurang & 19 & 29,7 \\
\hline & Jumlah & 64 & 100.0 \\
\hline
\end{tabular}

Tabel 5. Distribusi frekuensi partisipasi ibu hamil di wilayah kerja Puskesmas 2 Cilongok Kabupaten Banyumas

\begin{tabular}{cccc}
\hline & & Frekuensi \\
No & Partisipasi & $\begin{array}{c}\text { Prosentase } \\
(\%)\end{array}$ \\
\hline 1 & Berpartisipasi & 44 & 68,8 \\
2 & Tidak & 20 & 31,3 \\
& berpartisipasi & & \\
\hline & Jumlah & 64 & 100,0 \\
\hline
\end{tabular}

Berdasarkan tabel 5. diatas menunjukkan responden yang berpartisipasi dalam kelas ibu hamil sebanyak 44 ibu hamil $(68,8 \%)$, responden yang tidak berpartisipasi dalam 
kelas ibu hamil sebanyak 20 ibu hamil $(31,3 \%)$.

Analisis Bivariat

Tabel 6. Hubungan Tingkat Pengetahuan Ibu Hamil dengan Partisipasi Kelas Ibu di wilayah kerja Puskesmas 2 Cilongok Kabupaten Banyumas

\begin{tabular}{|c|c|c|c|c|c|c|c|c|}
\hline \multirow{3}{*}{$\begin{array}{l}\text { Penge } \\
\text { tahua } \\
n\end{array}$} & \multicolumn{4}{|c|}{$\begin{array}{c}\text { Partisipasi Kelas Ibu } \\
\text { Hamil }\end{array}$} & \multicolumn{2}{|c|}{ Total } & \multirow{3}{*}{$\mathrm{r}_{\mathrm{s}}$} & \multirow{3}{*}{$\rho$} \\
\hline & \multicolumn{2}{|c|}{$\begin{array}{l}\text { Berpartisi } \\
\text { pasi }\end{array}$} & \multicolumn{2}{|c|}{$\begin{array}{l}\text { Tidak } \\
\text { berpartis } \\
\text { ipasi }\end{array}$} & \multirow[t]{2}{*}{$\mathrm{N}$} & \multirow[t]{2}{*}{$\%$} & & \\
\hline & $\mathrm{N}$ & $\%$ & $\mathrm{~N}$ & $\%$ & & & & \\
\hline Kuran & 7 & 368 & 1 & 63 , & 1 & 10 & 0,5 & 0,0 \\
\hline g & 1 & 50,0 & 2 & 2 & 9 & 0 & 54 & 00 \\
\hline Cuku & 1 & 588 & 7 & 41 , & 1 & 10 & & \\
\hline $\mathrm{p}$ & 0 & & & 2 & 7 & 0 & & \\
\hline Baik & 2 & 96.4 & 1 & 36 & 3 & 10 & & \\
\hline & 7 & & & & 4 & 0 & & \\
\hline Total & 4 & 688 & 2 & 31 , & 6 & 10 & & \\
\hline I otal & 4 & 08,8 & 0 & 3 & 4 & 0 & & \\
\hline
\end{tabular}

Berdasarkan tabel 6. di atas menunjukkan responden yang pengetahuan baik dan berpartisipasi sebanyak 27 ibu hamil $(96,4 \%)$ sedangkan responden yang pengetahuan baik dan tidak berpartisipasi sebanyak 1 ibu hamil $(3,6 \%)$. Responden yang pengetahuan cukup dan berpartisipasi sebanyak $10 \mathrm{ibu}$ hamil $(58,8 \%)$ sedangkan responden yang pengetahuan cukup dan tidak berpartisipasi sebanyak 7 ibu hamil $(41,2 \%)$. Responden yang pengetahuan kurang dan berpartisipasi sebanyak $7 \mathrm{ibu}$ hamil $(36,8 \%)$ sedangkan responden yang pengetahuan kurang dan tidak berpartisipasi sebanyak 12 ibu hamil $(63,2 \%)$.

Dari hasil uji statistik hubungan tingkat pengetahuan dengan partisipasi kelas ibu hamil dapat diketahui bahwa hasil $\rho$ value sebesar $0,000<\rho=0,05$ sehingga Ho ditolak dan $\mathrm{Ha}$ diterima yang artinya adanya hubungan antara pengetahuan dengan partisipasi kelas ibu hamil dengan kategori keeratan hubungan 0,554 yang berarti memiliki kekuatan hubungan sedang.

Berdasarkan hasil penelitian pada tabel 4 menyatakan bahwa dari keseluruhan jumlah responden yaitu 64 ibu hamil, terdapat 19 responden $(29,7 \%)$ yang memiliki pengetahuan kurang, 17 responden (26,6\%) memiliki pengetahuan cukup, dan 28 responden $(43,8 \%)$ memiliki pengetahuan baik. Penelitian ini menunjukan bahwa ibu hamil memiliki pengetahuan baik tentang kelas ibu hamil. Pengetahuan baik pada responden ini dipengaruhi oleh cukupnya informasi atau materi kelas ibu hamil yang diberikan oleh bidan dalam kegiatan kelas ibu hamil, serta pengalaman ibu hamil sudah pernah mengikuti kelas ibu hamil.

Hasil dari tabel 4 menunjukan bahwa jumlah responden yang memiliki pengetahuan kurang hampir sama dengan jumlah responden yang memiliki pengetahuan cukup. Setelah dilakukan penelitian didapatkan masih kurangnya pengetahuan responden pada kuesioner tentang materi pada pertemuan pertama yaitu perawatan kehamilan dan perubahan tubuh selama kehamilan karena ibu hamil paling banyak pada usia kehamilan trimester 2, sehingga materi yang masih dikuasai adalah pada materi pertemuan ke-2. Hal lain pada kuesioner tentang keikutsertaan suami atau keluarga pada kelas ibu hamil tidak mengikuti, hal ini karena ibu hamil mengetahuai bahwa yang ikut hanya ibu hamil saja, tidak melibatkan keluarga.

Pengetahuan adalah merupakan hasil 'tahu' dan ini terjadi setelah orang melakukan pengindraan melalui panca indra yakni penglihatan, pendengaran, penciuman, rasa dan raba. Sebagian besar pengetahuan manusia diperoleh melalui mata dan telinga. Pengetahuan atau kognitif merupakan dominan yang sangat penting untuk terbentuknya tindakan seseorang (overt behavior). Pengetahuan itu sendiri dipengaruhi oleh usia, pendidikan, pekerjaan dan lingkungan yang menyebabkan pola pikir dalam kehidupan berbeda-beda dan menghasilkan pribadi yang unik dalam menjalani kehidupan. ${ }^{4}$

Pengalaman merupakan guru yang terbaik. Pepatah tersebut dapat diartikan bahwa pengalaman merupakan sumber pengetahuan, atau pengalaman itu suatu cara untuk memperoleh kebenaran pengetahuan, oleh sebab itu pengalaman pribadipun dapat digunakan sebagai upaya untuk memperoleh pengetahuan. ${ }^{4}$ Hasil penelitian ini dapat diketahui bahwa tingkat pengetahuan ibu hamil di Puskesmas 2 Cilongok Kabupaten Banyumas mengenai kelas ibu hamil sudah tergolong baik. Hal ini terjadi karena selama mengikuti kelas ibu hamil responden telah mendapatkan informasi, saling berinteraksi dan berbagi pengalaman antar peserta (ibu hamil dengan ibu hamil) maupun dengan tutor/bidan tentang kehamilan, perubahan dan 
keluhan selama kehamilan, perawatan kehamilan, persalinan, perawatan nifas, KB pasca persalinan, perawatan bayi baru lahir, mitos/kepercayaan/adat istiadat setempat, penyakit menular dan akte kelahiran. Bagi responden yang pengetahuannya cukup disebabkan kurang mendapatkan informasi dan kesalahan dalam mengintepretasikan informasi yang diperolehnya selama mengikuti kelas ibu hamil. Hal ini sesuai dengan teori bahwa informasi merupakan sumber utama untuk memperoleh pengetahuan. $^{4}$

Pengetahuan baik juga dipengaruhi oleh faktor pengalaman, ada beberapa faktor lain yang mempengaruhi pengetahuan responden, seperti pendidikan, pekerjaan, umur, lingkunagn dan sosial budaya. ${ }^{10}$

Pengetahuan ibu hamil tentang kelas ibu hamil dari 76 ibu hamil sebagian besar responden mempunyai pengetahuan yang cukup yaitu sebanyak 32 (42,1\%), pengetahuan kurang yaitu sebanyak 21 orang $(27,6 \%)$, dan pengetahuan baik yaitu sebanyak 23 (30,3\%). Pengetahuan cukup pada responden sama seperti penelitian ini di pengaruhi oleh informasi atau materi kelas ibu hamil yang diberikan oleh bidan dalam kegiatan kelas ibu hamil. ${ }^{9}$

Berdasarkan hasil penelitian pada tabel 4. menyatakan bahwa terdapat 44 responden $(68,8 \%)$ yang berpartisipasi dan 20 reponden $(31,3 \%)$ tidak berpartisipasi. Responden yang berpartisipasi dipengaruhi oleh informasi yang telah didapatkan serta pengalaman. Pengetahuan yang dimiliki oleh responden juga mempengaruhi ibu hamil untuk berpartisipasi dalam kelas ibu hamil. Ibu hamil yang paling banyak berpartisipasi pada usia kehamilan trimester $2(60,9 \%)$.

Partisipasi adalah peran serta aktif dalam kegiatan. Peran serta dilakukan secara paripurna meliputi menetapkan masalah, merumuskan perencanaan, serta melaksanakannya. Peran serta dapat dilakukan dari kelompok kecil sampai nantinya dapat diperluas sampai kelompok besar. $^{4}$

Responden yang berpartisipasi cenderung memiliki penegetahuan baik tentang kelas ibu hamil. Beberapa faktor yang mempengaruhi masyarakat untuk mengikuti proses partisipasi adalah pengetahuan dan keahlian, pekerjaan, pendidikan, jenis kelamin, dan kepercayaan terhadap budaya tertentu. ${ }^{8}$

Faktor-faktor eksternal ini dapat dikatakan petaruh (stakeholder), yaitu semua pihak yang berkepentingan dan mempunyai pengaruh terhadap program ini. Petaruh kunci adalah siapa yang mempunyai pengaruh yang sangat signifikan, atau mempunyai posisi penting guna kesuksesan program. ${ }^{7}$

Partisipasi ibu hamil tentang kelas ibu hamil di wilayah kerja Puskesmas 2 Cilongok Kabupaten Banyumas cenderung berpartisipasi, hal ini dikarenakan tingkat pengetahuan ibu hamil cenderung baik, serta dari segi pendidikan ibu hamil yang rata-rata berpendidikan SMP sebanyak 28 ibu hamil $(43,8 \%)$, sesuai dengan faktor dari partisipasi. Pada sebuah penelitian menunjukan bahwa yang berpartisipasi dipengaruhi oleh faktor usia, pendidikan, serta pekerjaan, hal ini sama dengan penelitian yang telah dilakukan. Faktor pengetahuan ibu hamil tentang kelas ibu hamil juga mempengaruhi partisipasi kelas ibu hamil, serta lokasi atau tempat pelaksanaan kelas ibu hamil tidak menjadi halangan bagi para ibu hamil untuk aktif berpartisipasi dalam kelas ibu hamil. Ada beberapa faktor lain yaitu mengenai usia ibu hamil bahwa usia tidak menghalangi ibu hamil untuk berpartisipasi dalam pelaksanaan kelas ibu hamil, faktor kebiasaan yang dilakukan ibu hamil pada saat ada jadwal kelas ibu hamil responden akan langsung berpartisipasi dalam kelas ibu hamil tersebut. Ibu hamil yang berpartisipasi juga dipengaruhi oleh informasi serta pengalaman yang sudah didapatkan sebelumnya, sehingga ibu hamil tersebut berpartisipasi dalam kelas ibu hamil. ${ }^{6}$

Berdasarkan analisa bivariat dengan uji statistic Spearman rho didapatkan nilai signifikasi (p) yang besarnya 0.000 dibandingkan dengan $\alpha: 5 \%$, maka $\mathrm{p}<0.05$ sehingga $\mathrm{Ha}$ diterima yang artinya ada hubungan antara pengetahuan dengan partisipasi kelas ibu hamil. Dengan nilai $r_{s}$ 0,554 artinya $55,4 \%$ partisipasi dipengaruhi oleh pengetahuan dengan nilai keeratan hubungan sedang dan sisanya itu dipengaruhi oleh faktor-faktor lain seperti pengalaman, pendidikan, usia, pekerjaan, kepercayaan dan sosial. Arah hubungan dalam penelitian ini yaitu positif yang artinya semakin tinggi 
pengetahuan ibu hamil, semakin tinggi partisipasi dalam kelas ibu hamil. Hal ini sama seperti penelitian dari Uswatun chasanah bahwa arah hubungannya positif yaitu semakin tinggi pengetahuan semakin tinggi motivasi ibu hamil untuk mengikuti kelas ibu hamil. ${ }^{9}$

Hasil ini sesuai dengan pendapat yang menyatakan bahwa pengetahuan akan menimbulkan kesadaran dan akhirnya menyebabkan orang berperilaku sesuai dengan pengetahuan yang dimilikinya. Keterbatasan pengetahuan akan menyulitkan seseorang memahami pentingnya kemajuan informasi mengenai kesehatan dan perubahan sikap serta perilaku seseorang atau kearah yang menguntungkan. ${ }^{4}$

Seorang ibu hamil yang berpengetahuan baik tentang kelas ibu hamil akan berpartisipasi dalam kelas ibu hamil. Sedangkan ibu hamil yang berpengetahuan kurang tidak akan berpartisipasi dalam kelas ibu hamil sehingga dengan adanya hal tersebut perlu dilakukan pemberian informasi tentang pelaksanaan kelas ibu hamil.

Dasar pengetahuan yang dimiliki akan mempengaruhi seluruh lingkungan dari masyarakat tersebut. Hal ini membuat masyarakat memahami ataupun tidak terhadap tahap-tahap dan bentuk dari partisipasi yang ada. Pengetahuan merupakan domain penting dalam membentuk suatu tindakan, sedangkan partisipasi diartikan sebagai peran serta aktif dalam kegiatan. ${ }^{8}$

\section{Kesimpulan}

Ibu hamil di di wilayah kerja Puskesmas 2 Cilongok Kabupaten Banyumas memiliki pengetahuan yang baik tentang kelas ibu hamil sebesar $(43,8 \%)$. Ibu hamil lebih banyak berpartisipasi $(68,8 \%)$ dalam kelas ibu hamil dibandingkan dengan yang tidak berpartisipasi (31,3\%). Ada hubungan yang bermakna antara pengetahuan dengan partisipasi kelas ibu hamil dengan $(\rho=0,000)$ rs sebesar 0,554 dengan keeratan hubungan yang sedang. Arah hubungannya positif yang artinya semakin tinggi pengetahuan ibu hamil, semakin tinggi partisipasi dalam kelas ibu hamil.

\section{Daftar Pustaka}

[1] Departemen Kesehatan Republik Indonesia. 2012. Pegangan Fasilator Kelas Ibu Hamil. h. 4.

[2] Departemen Kesehatan Republik Indonesia. 2012. Pedoman Pelaksanaan Kelas Ibu Hamil. h. 3.

[3] Ermalena. 2017. Indikator Kesehatan $S D G$ 's di Indonesia. Disampaikan dalam Diskusi Panel "Pengendalian Tembakau dan Tujuan Pembangunan Indonesia". Jakarta : DPR - RI.

[4] Notoatmodjo, Soekidjo. 2005. Promosi Kesehatan Teori dan Aplikasi. Jakarta. Penerbit: PT. Rineka Cipta. h. 3, 13, 143, 271.

[5] Notoatmodjo, Soekidjo. 2012. Promosi Kesehatan dan Perilaku Kesehatan. Jakarta. Penerbit: Rineka Cipta.

[6] Nurkatamso, Agus dan Umi Listyaningsih. Tingkat Partisipasi Masyarakat dalam program Fisik Program Nasional Pemberdayaan Masyarakat Mandiri Pedesaan di Kecamatan Nanggulan Kabupaten KulonpProgo. Yogyakarta: Jurnal Bumi Indonesia; 2013.

[7] Sunarti. 2003. Partisipasi Masyarakat dalam Pembangunan Perumahan secara Kelompok. Jurnal Tata Loka. Semarang: Planologi UNDIP. h. 9.

[8] Suryawan, B. 2004. Karakteristik Zeolit Indonesia sebagai Adsorbenn Uap Air. Disertasi. Jakarta: Universitas Indonesia. h. 27.

[9] Uswatun Chasanah, Ratifah. Hubungan Pengetahuan Ibu Hamil Tentang Kelas Ibu Hamil Dengan Motivasi Mengikuti Kelas Ibu Hamil Di Puskesmas 2 Mandiraja Kabupaten Banjarnegara. Banjarnegara: Jurnal Ilmiah Kebidanan; 2013.

[10] Wawan, A dan Dewi, M. 2011. Teori dan Pengukuran Pengetahuan, Sikap, dan Perilaku Manusia. Yogyakarta. Penerbit: Nuha Medika. 